\title{
PERCEPÇÃO DOS PROFISSIONAIS CONTÁBEIS SOBRE A IMPORTÂNCIA DA CONTABILIDADE AMBIENTAL ${ }^{1}$
}

\author{
Mikael Vieira Veroneze ${ }^{2}$, Vanderléia Aparecida Silva ${ }^{3}$, Flávio Amaral \\ Oliveira $^{4}$, Edinéia Souza Nunes ${ }^{5}$, Margarida Alves Rocha ${ }^{6}$
}

\section{RESUMO}

Este estudo teve como objetivo evidenciar a importância dada a contabilidade ambiental pelos profissionais contábeis de Tangará da Serra - MT,. Para tanto, foi realizada uma pesquisa de campo, através da aplicação de 37 questionários com perguntas fechadas sobre contabilidade ambiental, aos contadores de cada escritório. Após a coleta, os dados foram tabulados, e, realizada análise descritiva. Através da pesquisa constatou-se que os escritórios já reconhecem a importância da contabilidade ambiental, todavia o nível de conhecimento foi considerado insuficiente, pois não exercem nenhuma atividade relacionada a essa temática em seu cotidiano, em função de não existir nenhuma demanda.

Palavras chave: Conhecimento Contábil. Sustentabilidade. Responsabilidade Ambiental.

\begin{abstract}
This study aimed to highlight the importance of environmental accounting for the accounting professionals of Tangara da Serra - MT. Therefore, a field survey was carried out by applying 37 questionnaires with closed questions on environmental accounting, each office counters. After collection, the data were tabulated, and carried out a descriptive analysis. Through research it was found that the offices have recognized the importance of environmental accounting, but the level of knowledge was considered insufficient because it does not carry out any activity related to this theme in their daily lives, in there is no demand function.
\end{abstract}

Keywords: Accounting Knowledge. Sustainability. Environmental Responsibility.

\section{INTRODUÇÃO}

Com o descobrimento de que os recursos da natureza, quando mal utilizados, são esgotáveis e, entretanto, finitos, outros aspectos passaram a fazer parte do objetivo da entidade. Os gestores passaram a se preocupar não somente com a gestão de seus negócios, mas também com as pessoas e com o meio ambiente em que estão inseridas (YAMAGUCHI, 2012).

\footnotetext{
${ }^{1}$ Trabalho de Conclusão de Curso defendido em 25/06/2014 no Curso de Ciências Contábeis - Campus de Tangará da Serra - MT

${ }^{2}$ Unemat campus de Tangará da Serra-MT, acadêmico concluinte do curso de Ciências Contábeis.

${ }^{3}$ Especialista em Auditoria e Perícia Contábil, professora do curso de Ciências Contábeis da UNEMAT Campus de Tangará da Serra. Atualmente é mestranda do mestrado Profissional em Ciências Contábeis FUCAPE.

${ }^{4}$ Contador da prefeitura de Tangará da Serra/MT

${ }^{5}$ Contadora e Mestra em Meio Ambiente e Sistema de Produção Agrícola-UNEMAT campus de Tangará da Serra/MT

${ }^{6}$ Professora Efetiva da UNEMAT, campus de Tangará da Serra/MT. 
Mas a preocupação com os riscos e danos ao meio ambiente estão além dos limites dos grupos ambientalistas e da sociedade, que não focam somente na preservação dos recursos ainda existentes, mas alertam o mundo, principalmente as empresas, quanto à consciência sobre as novas riquezas (MACIEL et al., 2009).

Desta forma, a contabilidade ambiental tem como foco o patrimônio ambiental sendo composto pelos bens, direitos e as obrigações ambientais das empresas. Nesse sentido, fornece informações contábeis dos eventos ambientais ativos e passivos que alteram as situações patrimoniais das empresas, ou seja, identifica, mensura e até mesmo evidencia os acontecimentos ambientais (SILVA et al., 2013).

Segundo Silva et al., (2013), a contabilidade ambiental possui potencialidade para auxiliar os administradores na missão de aprimorar a utilização dos recursos naturais, sendo usada para evidenciar a responsabilidade ambiental da entidade, através da apresentação de relatórios contábeis onde devem ser demonstrados, de forma clara, e autêntica, os gastos realizados com controle ambiental. De acordo com Silva et al. (2013) a contabilidade ambiental é ainda pouco utilizada nas entidades, mas as questões ecológicas, sociais e ambientais, vêm fazendo com que os contabilistas e gestores empresariais passem a apreciálas nos sistemas contábeis e gestão, oferecendo a oportunidade ao reconhecimento da contabilidade ambiental.

Desta forma, o objetivo da pesquisa consistiu em evidenciar a importância dada à contabilidade ambiental pelos profissionais contábeis de Tangará da Serra - MT. Portanto, justifica-se o estudo em razão de que, as pesquisas realizadas neste assunto necessitam aprofundar a abrangência sobre a determinação e a estruturação dos eventos envolvidos no incremento dos custos ambientais, pois os estudos publicados não evidenciam conceitualmente e metodologicamente de como aplicar a contabilidade ambiental (SCHNEIDER; MEINS, 2012; ELKINGTON, 2012; SILVA et al., 2013; GUPTA; HARNISCH, 2014).

\section{REFERENCIAL TEÓRICO}

\subsection{Contabilidade Ambiental}

O objeto da contabilidade é o patrimônio. Desta forma, define-se, como o objeto de estudo da contabilidade ambiental as informações contábeis referentes aos eventos do meio 
ambiente, que é declarado o patrimônio da humanidade. Assim, a contabilidade ambiental demonstra as receitas, as despesas e os custos ambientais referente as atividades da entidade, e evidencia todo o patrimônio ambiental da mesma, sendo o ativo e o passivo ambiental (MARTINS; BELLO; OLIVEIRA; 2010).

O surgimento desta nova área contábil veio para auxiliar os contadores no desenvolvimento de ferramentas voltadas à interação com o meio ambiente. Faroni et al. (2010) enfatizam, que a contabilidade ambiental não se trata de uma nova contabilidade, mas sim um conjunto de informações que expõe em termos econômicos as ações praticadas pelas empresas com objetivo de mensurar seu patrimônio ambiental. Portanto, fornecendo aos seus usuários informações econômicas e financeiras no que se refere à proteção, preservação e recuperação ambiental, além de proporcionar relatórios que auxiliem seus gestores na melhor tomada de decisão para a empresa (FARONI et al., 2010).

A contabilidade ambiental necessita atuar conjuntamente com as esferas ambientais, na tentativa de determinação e reconhecimento dos fatos que estão relacionados ao meio ambiente, no intuito de que sejam transmitidas para suas demonstrações contábeis de forma objetiva e transparente. Assim, as entidades devem mensurar seus eventos ambientais e constituir políticas, com o objetivo de tornar mínimo, os efeitos ocasionados pelos seus impactos ambientais negativos e fomentar os positivos (OLIVEIRA et al., 2012).

A preocupação com os impactos ambientais já vinham sendo discutidas pelo mundo desde a década de 50, sendo considerado objeto de estudos e preocupação internacional, mas conforme explica Maciel et al. (2009), a contabilidade ambiental surge como uma nova ferramenta contábil em fevereiro de 1998, com o término do "Relatório Financeiro e contábil sobre passivos e custos ambientais" desenvolvido pelo Grupo de Trabalho Intergovernamental das Nações Unidas de Especialistas em Padrão Internacionais de Contabilidade e Relatórios.

Diante do exposto, apresenta-se as três grandes áreas ambientais que classificam as ferramentas da contabilidade ambiental como produção (aspectos), direção (direção) e meio ambiente (impactos), assim temos:

\footnotetext{
Aspectos ambientais são os elementos específicos das atividades, produtos ou serviços da empresa que podem interagir positivamente ou negativamente com o meio ambiente; decisões ambientais incluem todas as políticas, estratégias, planos de ação e instrumentos de trabalho que a direção da empresa adota para desenvolver uma gestão ambiental determinada da companhia. Os impactos ambientais definemse como toda troca do meio ambiente, seja adversa ou benéfica ao seu resultado, total ou parcialmente, das atividades, produtos ou serviços da empresa (KRAEMER, 2010, p. 2).
} 
Assim, a Contabilidade Ambiental nada mais é do que a parte da Ciência Contábil que mensura e evidencia todo componente patrimonial que uma empresa possui e que esteja integrada com o meio ambiente, fornecendo informações fundamentais no tocante à responsabilidade ambiental e social que a entidade necessita praticar, tanto com a sociedade, como quanto ao meio ambiente (RODRIGUES; PEREIRA, 2013).

\subsection{Responsabilidade Ambiental}

A responsabilidade ambiental das entidades é o compromisso que ela assume com base nos aspectos ambientais em suas tomadas de decisões, envolvendo sensibilização e compromisso ambiental, medição e auditoria, informação transparente, significando ir muito além do cumprimento de regulamentação (BISSCHOP, 2010). Logo, a responsabilidade ambiental pode ser resumida como a responsabilidade das entidades para as várias partes interessadas em saberem e conhecerem sobre os efeitos ambientais de suas atividades e as obrigações em curto e longo prazo para com o meio ambiente a fim de evitar a afetar a sustentabilidade das gerações futuras (BISSCHOP, 2010).

Segundo Kim, Nam e Kang (2010) as entidades tentam utilizar seus sites para o cumprimento da responsabilidade ambiental e, consequentemente, para construir relações públicas positivas com a sociedade. Constataram ainda, que as inquietações ambientais incluem governança ambiental, recursos de gestão de resíduos, manejo de ecossistemas e mudanças climáticas. Além disso, realizam publicações em seus websites para construir e mostrar a imagem positiva e para cumprir obrigações colocadas pela regulamentação das leis ambientais.

\subsection{Balanço Ambiental}

O balanço ambiental surge dentro da contabilidade ambiental com instrumento que visa melhor entendimento e integração entre a empresa e o meio ambiente e a sociedade. De acordo com Pereira; Couto e Galvão (2009), este demonstrativo informa o grau de envolvimento da gestão empresarial no desenvolver de ações eficientes com o meio ambiente, deixando evidente, toda e qualquer interação da entidade com o meio ambiente para análise.

O Conselho Federal de Contabilidade (CFC) manifestou interesse sobre o tema através das Normas Brasileiras de Contabilidade Técnica (NBC T), aprovando a NBC T 15, tratando das informações de natureza social e ambiental, abordando as normas da divulgação destas. 
Para transformar numa situação de compromisso, foi imposta pela NBC T 15 Informações de Natureza Social e Ambiental, criada pela Resolução CFC n ${ }^{0}$ 1.003, em 19 de agosto de 2004, a obrigatoriedade da Demonstração de Informações de Natureza Social e Ambiental a partir de $1^{\circ}$ de janeiro de 2008. Distribuídos em várias formas de evidenciação, tais como, bens e direitos ambientais, obrigações ambientais, ganhos ambientais e gastos ambientais, a NBC T 15 relaciona as seguintes informações a serem divulgadas:

a) investimentos e gastos com manutenção nos processos operacionais para a melhoria do meio ambiente; b) investimentos e gastos com a preservação e/ou recuperação de ambientes degradados; c) investimentos e gastos com a educação ambiental para empregados, terceirizados, autônomos e administradores da entidade; d) investimentos e gastos com a educação ambiental para a comunidade; e) investimentos e gastos com outros projetos ambientais; f) quantidade de processos ambientais, administrativos e judiciais movidos contra a entidade; g) valor das multas e das indenizações relativas a matéria ambiental, determinadas administrativa e/ou judicialmente; h) passivos e contingências ambientais (CFC, RESOLUÇÃO No $1.003,2004)$.

De acordo com Melo, Diniz e Batista (2012) os instrumentos normativos determinam a obrigatoriedade de elaboração de alguns demonstrativos sendo ambiental e social, determinando os deveres e obrigações das entidades em atentar-se com as questões ambientais desenvolvidas pelas entidades. Portanto, o balanço ambiental serve para registrar as ações das entidades em relação ao meio ambiente, se elas o afetam de maneira positiva ou negativa (SILVA et al., 2013). Desta forma, Tinoco e Kraemer (2011, p. 154) definem que os "Ativos ambientais são os bens adquiridos pela companhia que têm como finalidade controle, preservação e recuperação do meio ambiente".

Assim, os ativos ambientais são todos os bens da entidade que visam proteção e preservação do meio ambiente, já o passivo ambiental é toda obrigação contraída voluntária ou involuntariamente destinada à aplicação em ações de controle, preservação e recuperação do meio ambiente" (COSTA, 2012, p. 67). Segundo Tinoco e Kraemer (2011, p. 155) "Os passivos ambientais normalmente são contingências formadas em longo período, sendo despercebidos às vezes pela administração da própria empresa". Em relação às receitas ambientais, Costa (2012, p. 90) a define como "os recursos auferidos pela entidade, em decorrência da venda de seus subprodutos ou de material reciclados." 
Entretanto, na visão de Faroni et al., (2010), estes ativos ambientais são destinados ou provenientes da atividade de gerenciamento ambiental, ou seja, são os bens da empresa que visam à preservação, proteção e recuperação ambiental, para que estes recursos naturais ainda existentes possam ser usufruídos pelas gerações futuras. Assim, o balanço ambiental torna-se um espelho das atitudes e esforços em relação às atividades da empresa e seus efeitos no meio ambiente, onde através de seus ativos ambientais a empresa visa diminuir os prejuízos causados por suas atividades.

Diferentemente dos ativos e passivos ambientais, a empresa consegue realizar sua separação e destinação de acordo com sua finalidade, o patrimônio líquido ambiental apresenta maior complexidade no que tange a separação, conforme explica Maciel et al., (2009), esta obtenção de capital é originada do acúmulo de ativos e passivos ambientais, mas, embora existente, é de difícil separação, pois estes recursos são formados ao longo do tempo e utilizados pelas empresas sem distinção, tornando-se inviável e de pouco sentido realizar sua separação, tendo em vista que todo este patrimônio, seja ele ambiental ou não, é de propriedade da empresa.

\subsection{Custos e Despesas Ambientais}

Custos ambientais são os gastos em aplicação direta no sistema de gerenciamento ambiental do processo produtivo e nas atividades ecológicas da empresa (FARONI,2010). Lima et al. (2014) complementam, que estes custos devem estar ligados direta ou indiretamente às ações de prevenção ou recuperação do ambiente que a empresa está inserida, colocando em prática os princípios do desenvolvimento sustentável.

Esta classificação apesar de parecer simples, na maioria das vezes é contabilizada como despesa, pois, por mais que esta proteção ao meio ambiente venha a ter benefícios futuros, sua mensuração é difícil de ser feita com clareza (MACIEL et al., 2009). Estes custos muitas vezes esbarram na sua classificação, já que, pela sua natureza, na maioria dos casos são tratados como custos indiretos sendo direcionados a atividade normal das empresas como, por exemplo, os custos com depreciação, e para que seja considerado ambiental deverá ser direcionado ao processo sustentável, conforme Gonçalves et al. (2014) e Melo et al. (2016).

Já a despesa ambiental é definida como um desembolso voltado para descontaminação do meio ambiente. De acordo com Souza et al. (2015), são aquelas despesas que não estão 
relacionadas diretamente a atividade fim da empresa, mas pode resultar e beneficiar o patrimônio da entidade através de receitas ambientas.

Lima et al. (2014) explicam que estas despesas ambientais podem ser classificadas como operacionais, quando está empregada diretamente a preservação do meio ambiente, ou não operacionais derivadas de multas, sanções e indenizações. Assim, Melo et al. (2016) concluem que estas despesas se originam de atividades voltadas a área administrativa e de gerenciamento das empresas no âmbito ambiental.

\subsection{Receitas Ambientais}

$\mathrm{Na}$ visão de Faroni et al. (2010), receita ambiental origina-se do acréscimo de benefícios econômicos durante o exercício financeiro na forma de entrada de recursos ou decréscimo de exigibilidade, que resulta em aumento do patrimônio líquido.

Portanto, esta receita ambiental pode se originar de diversas formas, onde Lima et al. (2014) expõem que estes ganhos podem ser originados pela venda de resíduos, subprodutos poluidores ou até mesmo pela valorização do mercado oriundo do reconhecimento da sociedade pelas atividades e empenhos para com o meio ambiente. Estes produtos que são considerados resíduos de produção de uma empresa, consequentemente torna-se matéria prima essencial no processo produtivo de outra instituição (MELO et al., 2016).

Nota-se que, além das empresas exercerem seu papel desenvolvendo a preservação do meio ambiente, elas também conseguem obter resultados econômicos positivos em decorrência destas atividades de caráter ambiental, para Piau e Nepomuceno (2013), as práticas saudáveis para com meio ambiente não impedem que se obtenham receitas oriundas deste processo, mas este retorno lucrativo não deve ser considerado o objetivo principal da instituição.

\subsection{Exigências de Mercado: Vantagem Competitiva Estratégia}

A partir do crescimento das entidades e das mudanças tecnológicas, novos padrões e exigências foram criados. Assim, se presencia a importância de existirem processos adaptados á sustentabilidade, sendo assim garantido o bem-estar econômico, social e ambiental (PERLIN et al., 2013). A crescente preocupação da comunidade com ambiente em que está inserida conduz para os resultados negativos dos sistemas de produção, ou seja, pressionando para que as entidades assumam a suas responsabilidades no desenvolvimento sustentável. É 
fundamental, ressaltar que a questão sustentável não está desprendida do crescimento econômico, mas pode ser vista como um importante fator de geração de valor e vantagem competitiva (PERLIN et al., 2013).

A estratégia empresarial é a ação básica desenvolvida e estruturada pela entidade para atingir, de forma apropriada e diferenciada, os objetivos planejados para o futuro, no mais perfeito posicionamento da empresa perante seu ambiente. Pois, está relacionada com a arte de empregar adequadamente os recursos financeiros, humanos, físicos e tecnológicos, em vista a diminuição dos problemas e a potencialização do uso das oportunidades (OLIVEIRA, 2012).

Para Hitt, Ireland e Hoskisson (2011), estratégia é um conjunto interligado e coordenado de obrigações e ações, definido para explorar aptidões essenciais e alcançar vantagem competitiva. Está visão de que a vantagem competitiva surge basicamente das condições que uma entidade tem de criar valor para seus clientes e acionistas.

Segundo, Schneider e Meins (2012) as discussões sobre sustentabilidade são movidas pela noção básica de que o desempenho de uma entidade deve ser medido não apenas pelo lucro, mas também pela quantidade de danos/melhorias dos sistemas ecológicos e sociais de suas atividades. Portanto, a preservação ambiental além de trazer benefícios ao meio ambiente e ao homem, torna-se uma grande ferramenta de publicidade, garantindo assim uma melhor visibilidade à empresa diante do mercado e abrindo portas neste novo cenário mundial.

\subsection{Legislação Ambiental}

O Brasil possui uma ampla legislação ambiental, que segundo Wolff (2009), as leis que tratam do meio ambiente no Brasil estão entre as mais completas e avançadas do mundo. No início da década de 1990, a legislação brasileira cuidava separadamente dos bens ambientais de forma não relacionada assim com a aprovação da Lei de Crimes Ambientais, ou Lei da Natureza (Lei No 9.605 de 13 de fevereiro de 1998), a sociedade brasileira, os órgãos ambientais e o Ministério Público passaram a contar com um mecanismo de defesa que controlava e punia infratores que causassem danos ao meio ambiente. Desta forma, esta lei veio complementar a lei 6.398/81, a qual trata apenas de reparações civis decorrentes de atos danosos ao meio ambiente.

De acordo com Lei de Crimes Ambientais $\mathrm{N}^{0}$ 9.605/98, os crimes ambientais são classificados em: crimes contra fauna e flora - agressões cometidas contra animais silvestres 
e/ou destruir ou danificar espécies vegetais nativas de qualquer porte; poluições de patrimônio urbano e cultural - construção próxima ou em áreas de preservação permanente, sem autorização ou em discordância com a autorização concedida; crimes contra administração ambiental - declaração falsa, enganosa ou omissão de dados em processos de licenciamento ou autorização ambiental; Infrações administrativas - transgressão ou descumprimento de regras jurídicas no uso, gozo, promoção, e restauração do meio ambiente (BRASIL, 2010).

Além da lei 9.605/98, outra legislação que demonstra a preocupação com o meio ambiente é exposta na Constituição Federal, editada em 1988, no capítulo VI art. 225, a qual destaca a importância de preservação do meio ambiente, onde afirma que, "todos têm direito ao meio ambiente ecologicamente equilibrado, bem de uso comum do povo e essencial à sadia qualidade de vida, impondo-se ao poder público e à coletividade o dever de defendê-lo e preservá-lo para as presentes e futuras gerações".

Segundo Wolff (2009) a legislação ambiental brasileira tem criado e executado cada vez mais ações preventivas ao processo produtivo originado pelas empresas, tendo um rigoroso controle sobre o cumprimento das normas vigentes e assim desenvolvendo diretrizes e iniciativas capazes de priorizar a preservação dos recursos naturais tendo assim condição essencial para uma gestão ambiental empresarial eficiente.

\section{METODOLOGIA}

Quanto aos objetivos este estudo se caracteriza como descritivo, pois de acordo com Lima (2008), este método expõe características do fenômeno estabelecendo correlações entre variáveis. Sendo classificada de natureza quantitativa, pois de acordo com Gil (2011), corresponde a uma das formas de estudo que possibilita explicar um fenômeno através de sua exploração intensa e exclusiva, além de possibilitar a utilização de instrumentos numéricos e estatísticos para coleta e análise dos dados (JUNG, 2004).

Esta pesquisa procurou evidenciar a importância e o conhecimento da contabilidade ambiental para os escritórios de contabilidade de Tangará da Serra - MT. Buscou os principais conceitos do fenômeno que se desejou investigar, pois o pesquisador não se restringe somente a uma única fonte de informação, mas sim, a um conjunto de autores que o auxilie na construção e embasamento de sua pesquisa possibilitando que além da concretização da pesquisa, que se possa também atingir um nível interpretativo e analítico da questão (LIMA, 2008). 
A coleta de dados foi através de levantamento, pelo método survey, pois de acordo com Gil (2011), é um método de interrogação direta de pessoas cujo comportamento se deseja conhecer, sempre levando em consideração que nenhuma amostra é perfeita. Os dados foram levantados mediante pesquisa de campo, o qual consiste na observação dos fatos ou de possíveis informações que sejam úteis para a pesquisa (LAKATOS; MARCONI, 2010). Como instrumento de coleta de dados foi utilizado questionário fechado, com 17 (dezessete) perguntas elaboradas utilizando-se da opinião, conceitos e teorias sobre contabilidade ambiental.

Para universo da pesquisa, foram escolhidos os escritórios de contabilidade de Tangará da Serra - MT, tendo como população-alvo, somente os escritórios devidamente registrados no setor de alvará da prefeitura do município, totalizando 37 (trinta e sete) escritórios devidamente regularizados. A amostra selecionada foram os contadores responsáveis ou devidamente capacitado em cada um dos escritórios, a titulo informativo, buscou - se saber a idade dos contadores, observar a parilidade dos sexos diante do mercado contábil, a busca dos profissionais pela qualificação após a formação acadêmica e as atitudes e iniciativas dos contadores com base na contabilidade ambiental visando a preservação do meio em seu ambiente de trabalho.

O período de aplicação do questionário ocorreu durante o mês de abril de 2014, nos escritórios de contabilidade de Tangará da Serra - MT. Após a coleta de dados foi realizada a análise e interpretação, sumarizando e transformando as informações a fim de responder o problema do estudo, com objetivo de se descobrir as características do fenômeno estudado. Os dados da pesquisa após serem coletados, foram selecionados e tabulados e explicitados em tabelas e quadros.

\section{RESULTADOS}

\subsection{Perfis dos Contadores}

A pesquisa constatou o perfil de 37 profissionais contadores proprietários ou capacitados para atender os objetivos da pesquisa, dentro de cada escritório de contabilidade selecionado como amostra. Quanto à faixa etária dos entrevistados, as que mais se destacaram foram as de 26 a 30 anos (jovens) e acima de 40 anos (experientes), ambas com 32\%. Resultado este, que demonstrou paridade entre contadores jovens e experientes, respectivamente, atuantes no mercado tangaraense. 
Constatou-se que 51\% dos entrevistados são do sexo feminino e, os demais, masculino. Embora se observe competitividade entre os sexos, as mulheres se sobressaem e conforme dados divulgado pelo Conselho Federal de Contabilidade (CFC, 2014), 41\% dos profissionais registrados nesse órgão são do sexo feminino, enquanto os homens somam 59\%, sendo que destes $62 \%$ são bacharéis em Ciências Contábeis e $38 \%$ são técnicos em contabilidade. O Estado de Mato Grosso possui, de acordo com dados do CFC, 7.754 contadores, sendo $49,97 \%$ do sexo masculino e 50,03\% de mulheres, resultado bem próximo ao encontrado nessa pesquisa.

Tabela 1: Perfil dos Entrevistados

\begin{tabular}{|c|c|c|c|}
\hline Questões & Variáveis & Entrevistados & Percentuais \\
\hline \multirow{4}{*}{ Idade } & 20 anos a 25 anos & 3 & $8 \%$ \\
\hline & 26 anos a 30 anos & 12 & $32 \%$ \\
\hline & 31 anos a 40 anos & 10 & $27 \%$ \\
\hline & Acima de 40 anos & 12 & $32 \%$ \\
\hline Total & & 37 & $100 \%$ \\
\hline \multirow{2}{*}{ Sexo } & Masculino & 18 & $49 \%$ \\
\hline & Feminino & 19 & $51 \%$ \\
\hline Total & & 37 & $100 \%$ \\
\hline \multirow{2}{*}{$\begin{array}{c}\text { Graduação em instituição Pública ou } \\
\text { Privada } \\
\end{array}$} & Pública & 19 & $51 \%$ \\
\hline & Privada & 18 & $49 \%$ \\
\hline Total & & 37 & $100 \%$ \\
\hline \multirow{4}{*}{ Especialização } & Não Possui & 23 & $62 \%$ \\
\hline & Pós-Graduação & 12 & $32 \%$ \\
\hline & Mestrado & 2 & $5 \%$ \\
\hline & Doutorado & 0 & $0 \%$ \\
\hline Total & & 37 & $100 \%$ \\
\hline
\end{tabular}

Fonte: Dados da Pesquisa.

Diante da formação do contador observa-se, que 51\% dos profissionais são formados em instituições públicas e 49\% em instituições privadas. Quanto à especialização, $62 \%$ dos entrevistados informaram não ter nenhum tipo de especialização na área contábil, 32\% já possuem pós-graduação em algumas áreas como de contabilidade tributária, auditoria, controladoria, gestão de pessoas e perícia contábil, apenas $5 \%$ possui mestrado nas áreas de administração e tributária (TABELA 1).

Mesmo com um percentual de entrevistados considerável que possui algum tipo de especialização, observa-se, que nenhum dos escritórios possui contador com especialização em contabilidade ambiental, ou direcionada a tal, confirmando que esta é uma área da contabilidade ainda é pouco explorada pelos contadores do município Tangará da Serra - MT.

\subsection{A Importância e conhecimento da contabilidade ambiental para os escritórios}


Esta etapa do estudo foi desenvolvida com perguntas que demonstraram a importância e o conhecimento acerca do tema contabilidade ambiental para o escritório de contabilidade. A pesquisa indicou que grande parte dos escritórios (57\%) já tiveram contato com material de contabilidade ambiental, enquanto $43 \%$ afirmaram que não tiveram nenhum contato. Esse dado diverge do que se observa na Tabela 1, já que todos afirmaram possuir graduação em Ciências Contábeis, e muito provavelmente, cursaram disciplina que abordam o assunto ou, no mínimo, teriam lido sobre o assunto e/ou discutido sobre o tema contabilidade ambiental na graduação. Todavia, vai de encontro com Tabela 2 , onde $43 \%$ afirmaram que não participam de eventos direcionados a contabilidade ambiental.

Embora a contabilidade ambiental seja área da contabilidade ainda pouco explorada pelos escritórios, destaca-se que 57\% dos entrevistados buscam conhecimento e atualizações participando de eventos, palestras ou congressos onde o contexto contábil ambiental já se mostra presente (TABELA 2).

Tabela 2: Importância da Contabilidade Ambiental

\begin{tabular}{|c|c|c|c|}
\hline Questões & Variáveis & Entrevistados & Percentuais \\
\hline $\begin{array}{l}\text { Participaram de palestras, congressos ou } \\
\text { seminários sobre contabilidade ambiental }\end{array}$ & $\begin{array}{l}\text { Sim } \\
\text { Não }\end{array}$ & $\begin{array}{l}21 \\
16\end{array}$ & $\begin{array}{l}57 \% \\
43 \%\end{array}$ \\
\hline Total & & 37 & $100 \%$ \\
\hline $\begin{array}{c}\text { Materiais existentes sobre contabilidade } \\
\text { ambiental abordam o assunto de forma clara e } \\
\text { objetiva }\end{array}$ & $\begin{array}{l}\text { Não } \\
\text { Não sabe dizer } \\
\text { Sim } \\
\end{array}$ & $\begin{array}{c}16 \\
13 \\
8 \\
\end{array}$ & $\begin{array}{l}43 \% \\
35 \% \\
22 \% \\
\end{array}$ \\
\hline Total & & 37 & $100 \%$ \\
\hline $\begin{array}{l}\text { A relevância da contabilidade ambiental no } \\
\text { exercício da profissão contábil }\end{array}$ & $\begin{array}{l}\text { Grande Relevância } \\
\text { Relevância } \\
\text { Pouca Relevância } \\
\text { Sem Relevância } \\
\end{array}$ & $\begin{array}{c}5 \\
15 \\
13 \\
4 \\
\end{array}$ & $\begin{array}{l}14 \% \\
41 \% \\
35 \% \\
11 \% \\
\end{array}$ \\
\hline Total & & 37 & $100 \%$ \\
\hline $\begin{array}{l}\text { Ramo da contabilidade que tende a ser } \\
\text { destaque no futuro }\end{array}$ & $\begin{array}{c}\text { Contabilidade } \\
\text { Fiscal/Tributária } \\
\text { Contabilidade Gerencial } \\
\text { Contabilidade Ambiental } \\
\text { Contabilidade Custos } \\
\text { Contabilidade Rural } \\
\text { Contabilidade } 3^{\circ} \text { Setor } \\
\text { Outras } \\
\text { Não informaram } \\
\end{array}$ & $\begin{array}{l}16 \\
9 \\
4 \\
3 \\
3 \\
0 \\
0 \\
2 \\
\end{array}$ & $\begin{array}{c}43 \% \\
24 \% \\
11 \% \\
8 \% \\
8 \% \\
0 \% \\
0 \% \\
6 \% \\
\end{array}$ \\
\hline Total & & 5 & $100 \%$ \\
\hline $\begin{array}{c}\text { O escritório presta algum serviço na área } \\
\text { ambiental }\end{array}$ & $\begin{array}{l}\text { Sim } \\
\text { Não }\end{array}$ & $\begin{array}{c}0 \\
37 \\
\end{array}$ & $\begin{array}{c}0 \% \\
100 \% \\
\end{array}$ \\
\hline Total & & 37 & $100 \%$ \\
\hline
\end{tabular}

Fonte: Dados da pesquisa. 
Conforme Tabela 2, percebe-se que, apesar do crescente interesse dos entrevistados, o entendimento sobre o assunto ainda é pouco ou superficial, pois $43 \%$ disseram que os materiais disponíveis não expõem o assunto de forma clara e objetiva, 35\% não souberam informar, e apenas $22 \%$ responderam positivamente. Portanto, salienta-se que a maioria, $78 \%$ tiveram dificuldades em absorver as informações contidas nos materiais existentes.

A Tabela 2 demonstrou que a relevância da contabilidade ambiental já é entendida pelos escritórios de contabilidade, visto que, $41 \%$ consideram relevante essa nova área contábil, e 14\% a consideram de grande relevância para o exercício de sua profissão. Com a necessidade de serem sustentáveis em todos os aspectos, inclusive nas diversas áreas do conhecimento, os profissionais se deparam com a necessidade de adequarem-se às exigências do mercado de trabalho. Até o final do século XX, essa necessidade ainda não era percebida pelos profissionais, conforme resultados obtidos por Franco (1999), onde 35\% dos escritórios ainda viam como pouco relevante, e apenas $14 \%$ a tratavam com uma área de grande relevância para a contabilidade.

Tabela 3: Conhecimento sobre Contabilidade Ambiental

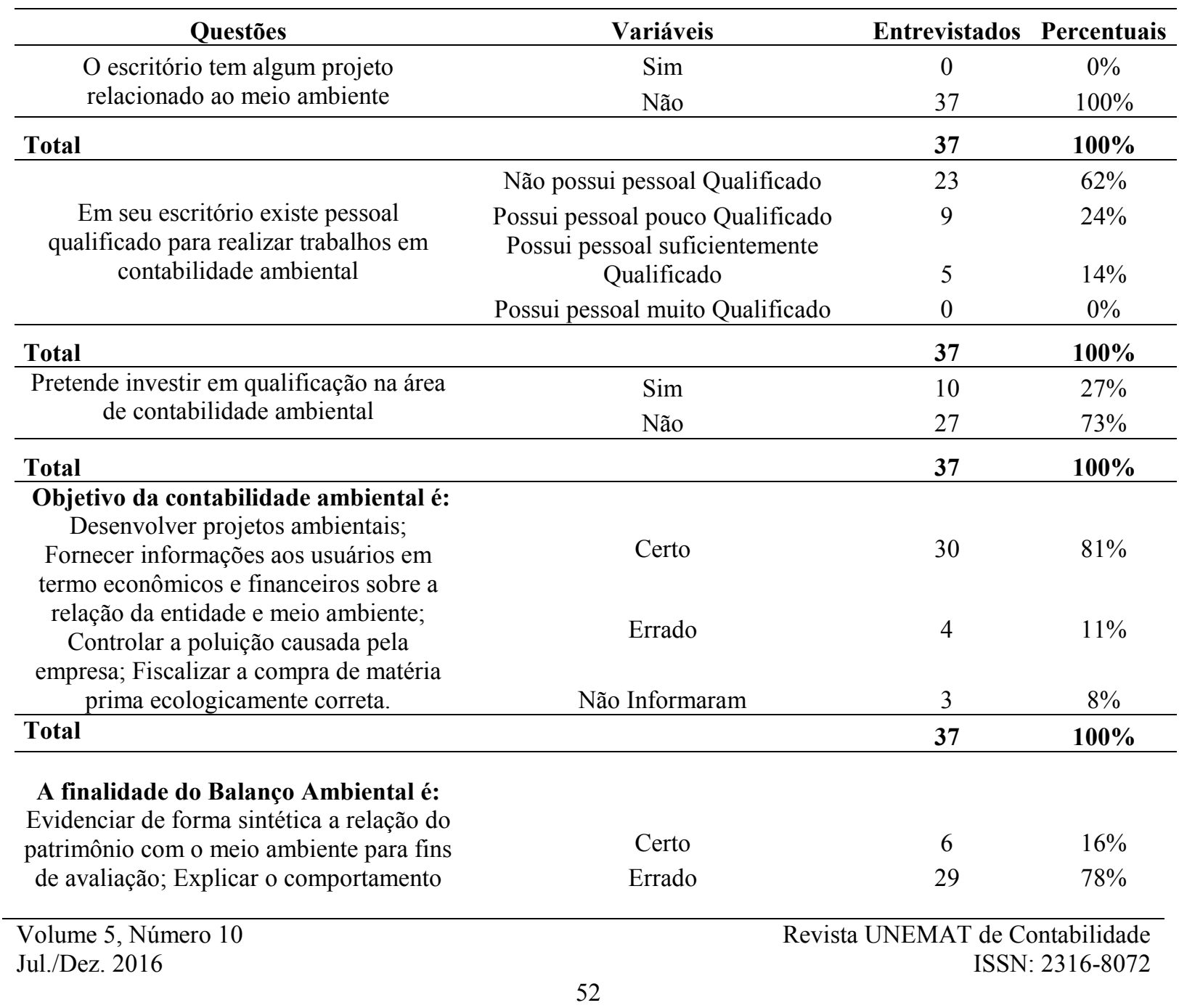


das empresas para com a sociedade;

Demonstrar o conjunto de bens adquiridos

pela empresa com a finalidade de

preservação; Demonstrar os gastos da

entidade em prol do meio ambiente;

Todas as alternativas estão corretas.

Não Informaram

Total

37

$5 \%$

Fonte: Dados da Pesquisa.

O entendimento acima é validado quando o ramo da contabilidade ambiental aparece na terceira posição (11\%), dentre os ramos da contabilidade a serem tendências futuras, e, demonstra que a mesma está ganhando espaço, pois conforme explicam Lourenço e Schroder (2003), o mercado está cada vez mais exigente e o consumidor mais informado, isso exige que as empresas possuam produtos que estejam inseridos no contexto ambiental.

Em primeiro lugar como expectativa de destaque futuro está a contabilidade fiscal/tributária com 43\%, seguida da contabilidade gerencial com $24 \%$, o que, respectivamente, pode ser explicado pela eficiência na forma de atuação do fisco e a necessidade das empresas serem cada vez mais competitivas para ser manterem no mercado.

Perguntados sobre a relevância no exercício da profissão (TABELA 2), a maioria afirmou que a contabilidade ambiental é relevante ou tem grande relevância. Entretanto, 35\% afirmaram ser de pouca relevância, o que pode ser explicado pelo fato de que a demanda por serviços na área ambiental é nula, ou seja, nenhum dos 37 entrevistados desempenham algum tipo de serviço voltado à contabilidade ambiental, e, por mais que os profissionais a reconheçam como área de relevância, a demanda pelos serviços ambientais ainda não faz parte do cotidiano dos escritórios de Tangará da Serra-MT.

A contabilidade ambiental gera benefícios tanto às empresas como aos clientes e, principalmente, ao meio ambiente, conforme afirma Kraemer (2001-2002), mas, o empresariado tangaraense ainda não sente a necessidade de serviços ambientais, talvez porque o empresariado seja formado, basicamente, por comércios varejistas e pequenos empreendedores, sendo que, a contabilidade ambiental é adotada pelas empresas de grande porte de acordo com a Resolução CFC n $\mathrm{n}^{0}$ 1.003/2004, conforme exposto por Campanhol, Andrade e Alves (2003).

Da mesma forma que a demanda por serviços de caráter ambiental não é realidade dos escritórios de contabilidade, os mesmos também não exercem a responsabilidade ambiental, pois, nenhum dos escritórios desenvolve algum tipo de projeto ambiental interno (TABELA 3), demonstrando que, por mais que a sustentabilidade esteja em evidência, a prestação de 
serviços e atitudes não são exercidas. Além de proporcionar aos usuários informativos oriundos destas atividades, conforme Kraemer (2001-2002), a contabilidade ambiental estimula a atividade e promove a responsabilidade ambiental, de acordo com Silva et al. (2009).

No que se refere à qualificação na área de contabilidade ambiental, nota-se que $62 \%$ dos escritórios não possuem pessoal qualificado para exercer tal função, e apenas $24 \%$ disseram que possuem pessoal pouco qualificado (TABELA 3). Este resultado retratou bem a realidade dos escritórios, pelo fato de não exercerem nenhum tipo de serviço de caráter ambiental não veem a necessidade de qualificação na área. Apenas $14 \%$ dos escritórios alegaram ter pessoal suficientemente qualificado a tal atividade (TABELA 3).

Apesar dos serviços ambientais ainda não serem requisitados, a qualificação e informação na área podem ser um diferencial no exercício da profissão, conforme explicam Rover e Borba (2006), possibilitando que o escritório esteja à frente dos concorrentes de Tangará da Serra e região.

Através da Tabela 3, verifica-se que apenas 27\% dos escritórios pretendem realizar investimentos em qualificação na área ambiental, e 73\% dos escritórios não pretendem realizar tal investimento, isso torna mais evidente que a importância dada à contabilidade ambiental não é suficiente ao ponto de buscar aperfeiçoamento para sua equipe. Mas, conforme Lourenço e Schroder (2003), a qualificação na área torna-se um diferencial para os escritórios diante desse ramo, que vem ganhando cada vez mais espaço no cenário contábil.

Para verificar o conhecimento dos profissionais, eles foram indagados sobre o objetivo da contabilidade ambiental (TABELA 3), onde $81 \%$ concordaram que o objetivo da contabilidade ambiental é de fornecer informações aos usuários em termos econômicos e financeiros sobre a relação da entidade com o meio ambiente. De acordo com Maciel et al. (2009), trata-se de uma nova ferramenta que vem para auxiliar o contador no desenvolver de seus relatórios ambientais. E, embora as atividades não façam parte da sua rotina de trabalho, o objetivo é entendido pela grande maioria dos escritórios.

Quando entrevistados com pergunta que abrange conhecimento mais aprofundado no assunto, os resultados foram diferentes se comparados com o anterior, pois, apenas $16 \%$ dos escritórios confirmaram que o balanço ambiental visa evidenciar de forma sintética a relação do patrimônio com o meio ambiente. Pereira, Couto e Galvão (2009), afirmaram que através desse balanço é demonstrado o grau de envolvimento da empresa com o meio ambiente. Dos 
entrevistados, 78\% não confirmaram as respostas, ou seja, demostrado falta de conhecimento, e $5 \%$ não informaram nenhuma das respostas.

O resultado não é diferente do apontado por Santos (2014), quando identificou que a maioria dos profissionais de escritórios de contabilidade entrevistados de Alta Floresta - MT não possui conhecimento satisfatório da contabilidade ambiental e alguns apenas ouviram falar por meios de comunicações sem muitos aprofundamentos.

Nota-se que é superficial o conhecimento dos escritórios quando comparado com características mais aprofundadas, e parte devido à pouca utilização cotidiana observada nos resultados de indagações anteriores. O quadro 01 retrata o fluxo de serviços que são mais solicitados pelos clientes.

Quadro 01: Ramo da Contabilidade mais solicitado pelos clientes

\begin{tabular}{|l|c|c|}
\hline & Ranking & Pontos \\
\cline { 2 - 3 } Contabilidade Fiscal/Tributária & $1^{\text {o }}$ & 190 \\
Contabilidade Rural & $2^{\mathrm{o}}$ & 155 \\
Contabilidade Gerencial & $3^{\mathrm{o}}$ & 145 \\
Contabilidade de Custos & $4^{\mathrm{o}}$ & 142 \\
Contabilidade Ambiental & $5^{\mathrm{o}}$ & 69 \\
Contabilidade 3 Setor & $6^{\mathrm{o}}$ & 31 \\
Outras (Comercial) & $7^{\mathrm{o}}$ & 31 \\
\hline
\end{tabular}

Fonte: Dados da Pesquisa.

Em primeiro lugar na demanda pelos cliente com 190 pontos, apareceu a contabilidade fiscal/tributária, seguida da contabilidade rural com 155 pontos, e em terceiro a contabilidade gerencial com 145 pontos (QUADRO 01), o que retrata a realidade dos serviços prestados pelos escritórios. Novamente, objetivando validar o conhecimento aprofundado em contabilidade ambiental, os entrevistados foram convidados à fazerem a correlação dos títulos contábeis estoque ambiental, imobilizado ambiental, passivo ambiental, receitas ambientais, custos ambientais e despesas ambientais com suas respectivas descrições.

O resultado, apresentado no Quadro 02, foi de que mesmo com algum conhecimento na área, $86 \%$ dos entrevistados erraram, e 14\% não informaram, demonstrando a carência de conhecimento aprofundado sobre a contabilidade ambiental.

Quadro 02: Área x Finalidade

\begin{tabular}{|c|l|c|c|}
\hline \multirow{2}{*}{ Estoque Ambiental; } & Certo & Entrevistados & Percentual \\
\cline { 2 - 4 } & Errado & 0 & $0 \%$ \\
& Não Informaram & 52 & $86 \%$ \\
\cline { 2 - 4 } & Total & $\mathbf{3 7}$ & $14 \%$ \\
\cline { 2 - 4 } & - Insumos utilizados visando reduzir e controlar os impactos \\
& ambientais;
\end{tabular}


Foi solicitado aos entrevistados que elegessem as principais vantagens de investir em projetos ambientais internos (QUADRO 3). Em primeiro lugar com 145 pontos, os escritórios veem tais esforços como uma ferramenta de marketing para a empresa, em segundo lugar com 119 pontos, a conquista de novos clientes, e em terceiro lugar com 117 pontos, a fidelização de clientes.

Observa-se no Quadro 3 que a visão dos profissionais dos escritórios de contabilidade sobre investir nesse tipo de projeto, em grande parte é voltada ao cliente. Não obstante, escritórios e clientes ainda não praticam projetos ambientais, conforme retro debatido. É importante salientar que, conforme Vellani e Ribeiro (2006), iniciativas ambientais além de trazer o cliente consciente para junto da empresa, também possibilita que as novas gerações desfrutem dos recursos ambientas.

Quadro 03: Vantagens para empresas que inventem em projetos ambientais internos

\begin{tabular}{|l|c|c|}
\hline & Ranking & Pontos \\
\cline { 2 - 3 } Marketing da empresa & 1 & 145 \\
Conquista novos clientes & 2 & 119 \\
Fidelização de clientes & 3 & 117 \\
Redução de custos & 4 & 107 \\
Fidelização de colaboradores & 5 & 73 \\
Não possui vantagens & 6 & 38 \\
\hline
\end{tabular}

Fonte: Dados da Pesquisa.

Segundo Silva et al. (2013) as entidades que tem maiores ganhos, se preocupam com as questões ambientais, pois, alguns consumidores dão preferência a seus produtos do que em comparação a outras entidades que não adotam nenhuma política ambiental em suas empresas.

\section{CONSIDERAÇÕES FINAIS}

A contabilidade ambiental surge com o objetivo de demonstrar os resultados da interação das atividades de empresas com o meio ambiente, buscando encontrar a melhor maneira para o desenvolvimento sustentável. Diante do exposto, os objetivos da pesquisa foram alcançados, pois demonstrou as particularidades e a importância da contabilidade ambiental para os escritórios de contabilidade de Tangará da Serra-MT. 
Quanto à problemática da pesquisa, concluiu-se, que a contabilidade ambiental apesar de ser um ramo da contabilidade, já tem sua importância reconhecida pelos escritórios, mas está se torna pequena visto que os escritórios não exercem nenhuma atividade relacionada a essa temática em seu cotidiano, simplesmente por haver nenhuma demanda.

Sugere-se nova pesquisa sobre o assunto direcionada a empresas do ramo de agronegócios do município de Tangará da Serra - MT, com base na legislação ambiental, Lei $\mathrm{n}^{\circ} 9.605 / 98$, buscando conhecer qual a importância dada pelas empresas a sanções penais sobre crimes ambientais, visto que, a contabilidade ambiental nos dias atuais tem sua aplicação voltada principalmente a este segmento.

\section{REFERÊNCIAS}

BRASIL, Constituição (1988). Constituição da República Federativa do Brasil. Brasília, DF, Senado, 1988. Disponível em: <

http://www.planalto.gov.br/ccivil_03/constituicao/constituicaocompilado.htm>. Acesso em 21 set. 2013.

BRASIL. Presidência da República. Casa Civil. Lei nº 9.605, de 12 de Fevereiro de 1998.

Dispõe sobre as sanções penais e administrativas derivadas de condutas e atividades lesivas ao meio ambiente, e dá outras providências. Disponível em: <

$<$ http://www.planalto.gov.br/ccivil_03/leis/L9605.htm>. Acesso em: 20 Set. 2013.

BISSCHOP, L. Corporate environmental responsibility and criminology. Law and Social Change, Belgium, v. 53, n. 4, p. 349-364, May 2010.

CAMPANHOL, Edna M.; ANDRADE, Priscila; ALVES, Marlene C. M. Rotulagem Ambiental: barreira ou oportunidade estratégica? Revista Eletrônica de Administração Facef, v. 2, n. 3, p. 1-13, Jul./Dez. 2003. Disponível em: <

periodicos.unifacef.com.br/index.php/rea/article/download/171/480>. Acesso em: 21 set. 2013.

CFC-Conselho Federal de Contabilidade. Profissionais Ativos nos Conselhos Regionais de Contabilidade agrupados por Gênero, 2014. Disponível em:

$<$ http://www3.cfc.org.br/spw/crcs/ConsultaPorRegiao.aspx?Tipo=0>. Acesso em: 10 mar. 2014.

CFC-Conselho Federal de Contabilidade. Brasil conta com meio milhão de profissionais da contabilidade, 2014. Disponível em: <

http://www.portalcfc.org.br/noticia.php?new=16758>. Acesso em: 10 mar. 2014.

CFC - Conselho Federal de Contabilidade. Resolução CFC n 1.003, de 19 de agosto de 2004, que aprova a NBC T 15 - Informações de Natureza Social e Ambiental. Disponível em: <http://www.portaldecontabilidade.com.br/nbc/res1003.htm>. Acesso em: 20 Jan. 2014. 
COSTA, Carlos A. G. Contabilidade ambiental: Contabilidade da gestão ambiental. São Paulo. Atlas, 2012.

ELKINGTON, J. Sustentabilidade: canibais com garfo e faca. Edição Histórica de 12 anos. São Paulo: M. Books do Brasil, 2012.

FARONI, Walmer; SILVEIRA, Suely F. R.; MAGALHÃES, Elizete A.; MAGALHÃES, Elenice M. A contabilidade ambiental em empresas certificadas pelas normas ISO 14001 na região metropolitana de Belo Horizonte-MG. Revista Árvore, Viçosa, v. 34, n. 6, Nov./Dez. 2010.

FRANCO, Hilário. Contabilidade na Era da Globalização: Temas Discutidos no XV Congresso Mundial de Contadores em Paris, 26 a 29-10-1997. São Paulo: Atlas, 1999.

GIL, Antônio C. Métodos e técnicas de pesquisa social. 6. ed. São Paulo: Atlas, 2011.

GONÇALVES, Marguit N.; LEONARDO, Vera S.; ABBAS, Katia; OKADI, Karina L.; MUNHOZ, Tayrine R. Gastos realizados para o controle dos impactos ambientais na atividade sucroalcooleira: identificação, representatividade e evidenciação. Revista Custos e @gronegocios on line, v. 10, n. 4, p. 345-368, Out./Dez. 2014.

GUPTA, Sujata, HARNISCH, Jochen. Cross-cutting Investment and Finance Issues. IPCC WGIII AR5, 2014. Disponível em:

<file:///C:/Users/PC/Downloads/ipcc_wg3_ar5_chapter16\%20(1).pdf>. Acesso: 05 jan. 2016.

HITT, M. A.; IRELAND, R.; HOSKISSON, R. E. Administração Estratégia. 7. ed. São Paulo: Cengage Learning, 2011.

JUNG, C. F. Metodologia para pesquisa \& Desenvolvimento. Rio de Janeiro: Axcel Books, 2004.

KIM, D.; NAM, Y. N.; KANG, S. K. An analysis of corporate environmental responsibility on the global corporate Web sites and their dialogic principles. Public Relations Review, USA, v. 26, n. 3, p. 285-288, May 2010.

KRAEMER, Maria E.P. Contabilidade Ambiental como sistema de informações. Revista Contabilidade Vista \& Revista. Belo Horizonte-MG, v. 12, n. 3, p. 71-92, dez. 2001.

, Maria E.P. Contabilidade Ambiental: O Passaporte para a Competitividade.

Revista Catarinense da Ciência Contábil, Florianópolis (SC), v. 1, n. 1, p. 25-40, dez/2001 $-\operatorname{mar} / 2002$.

, Maria E. P. Contabilidade ambiental: relatório para um futuro sustentável, responsável e transparente. Disponível em

$<$ http://www.alfinal.com/brasil/contabilidadeambiental.php>. Acesso em: 31 Maio 2010.

LAKATOS, Eva M.; MARCONI, Marina. A. Fundamentos de metodologia cientifica. 7. ed. São Paulo: Atlas, 2010. 
LIMA Francieli; MARQUES, John L.; ARAUJO, John L. S.; FREITAG, Viviane C.

Aplicabilidade da contabilidade ambiental nas indústrias química farmacêuticas do estado do Paraná. In: XXI CONGRESSO BRASILEIRO DE CUSTOS, 21, 2014, Natal, RN. Anais...

Natal: CBC, 2014. Disponível em: <

http://www.abcustos.org.br/congresso/view/5?ID_CONGRESSO=25> Acesso em 22 de

Fevereiro de 2016.

LIMA, Manolita C. Monografia: a engenharia da produção acadêmica. 2. ed. São Paulo: Saraiva, 2008.

LOURENÇO, Alex G.; SCHRODER, Débora S. Vale investir em responsabilidade social empresarial? Stakeholders, ganhos e perdas. Responsabilidade social das empresas, v. 2, 2003, São Paulo/Petrópolis: Instituto Ethos. Disponível em: <

http://ethos.org.br/_Uniethos/Documents/VALE\%20INVESTIR\%20EM\%20RESPONSABIL IDADE\%20SOCIĀL\%20EMPRESARIAL\%20_.pdf >. Acesso em: 21 set. 2013.

MACIEL Carolina V.; LAGIOIA, Umbelina C. T.; LIBONATI, Jeronymo J.; RODRIGUES, Raimundo N. Contabilidade Ambiental: um estudo exploratório sobre o conhecimento dos profissionais de contabilidade. Revista Contemporânea em Contabilidade, v. 1, n. 11, p. 137-157, 2009.

MARTINS, Jaqueline M. M.; BELLO, Luciandra R.; OLIVEIRA, Humberto R. Contabilidade ambiental: um estudo sobre sua importância e aplicabilidade em indústrias estabelecidas no Espírito Santo. Disponível em: $<$ http://cienciascontabeisbrasil.blogspot.com.br/2012/08/contabilidade-ambiental-um-estudo-sobre.html $>$. Acesso em: 22 Set. 2014.

MELO, Heitor D.; MELO, Janaina F. M.; PEREIRA, Alexandre W. R.; BARBOSA, Maria F. N. Analise da frequência dos itens ambientais nos instrumentos de evidenciação voluntária e obrigatória: estudo de caso nas empresas do segmento de siderurgia registradas na BOVESPA entre o período de 2008 e 2012. Revista Metropolitana de Sustentabilidade - RMS, v. 6, n ${ }^{\text {o }}$ 1, p. 24-42, Jan./Abr. 2016.

MELO, Janaina F. M.; DINIZ, Kalina L. A.; BATISTA, Fabiano F. Evidenciação ambiental no setor calçadista: um estudo nas empresas registradas na Bovespa. In: XIX CONGRESSO BRASILEIRO DE CUSTOS, 19, 2012, Bento Gonçalves (RS). Anais... Bento Gonçalves: CBC, 2012.

OLIVEIRA, Djalma P. R. Estratégia Empresarial e Vantagem Competitiva. 8. ed. São Paulo: Atlas S. A., 2012.

OLIVEIRA, José R.; SOUZA, Romina B. L.; SOUZA, Luciana S.; ARAÚJO, Tamires S. A Contabilidade Ambiental como Fator Econômico: um Estudo de Caso em uma Empresa de Manejo Florestal no Estado de Roraima. In: SIMPÓSIO DE EXCELÊNCIA EM GESTÃO E TECNOLOGIA - SEGET, 2012, Resende - Rio de janeiro (RJ). Anais... Rio de Janeiro: AEDB, 2012. Disponível em: $<$ http://www.aedb.br/seget/arquivos/artigos12/13616589.pdf $>$. Acesso em: 20 Jan. 2014. 
PERLIN, Ana Paula; GUEDES, Gisele; NUNES, Manuel; FERREIRA, Paula. Indicadores de sustentabilidade da indústria de cortiça portuguesa. Revista Portuguesa e Brasileira de Gestão. v. 12, n. 3, p. 47-56, Jul./Set. 2013.

PEREIRA, Viviane P; COUTO, Jorge G.; GALVÃO Henrique M., Balanço Ambiental: ferramenta de crescimento sustentável. Revista de administração da Fatea, v. 2, n. 2, p. 47 60, Jan./Dez. 2009.

PIAU, Amanda J. J.; NEPOMUCENO, Valério. Contabilidade ambiental: uma análise das evidenciações das empresas brasileiras do setor de papel e celulose. Revista Perquirere, v. 10, n. 2, p. 140-157, Dez. 2013.

RODRIGUES, Leonardo A.; PEREIRA, Ivone V. Contabilidade ambiental e sua evidenciação. Disponível em < http://www.cpgls.ucg.br/ArquivosUpload/1/File/CPGLS/IV\%20MOSTRA/

NEGCIO/Contabilidade\%20Ambiental\%20e\%20a\%20sua\%20Evidenciao.pdf $>$ Acesso em: 19 ago. 2013.

ROVER, Suliani; BORBA, José Alonso. A evidenciação das informações ambientais nas Demonstrações Contábeis das empresas que atuam no Brasil e que negociam ADR's na Bolsa de Valores dos Estados Unidos: uma análise das DFP's (CVM) e do relatório 20-F (SEC). In: VI CONGRESSO USP DE INICIAÇÃO CIENTÍFICA EM CONTABILIDADE, 6, 2006, São Paulo (SP) Anais... São Paulo: FEA/USP, 2006.

SANTOS, Heloisa L. Contabilidade Ambiental: Percepção dos profissionais contábeis da cidade de Alta Floresta. Revista Eletrônica da Faculdade de Alta Floresta (REFAF), v. 4, n. 2, p. 146-164, 2014. Disponível em:

$<$ http://faflor.com.br/revistas/refaf/index.php/refaf/article/view/169/pdf >. Acesso: 20 Jan. 2014.

SILVA, Francisca R. C.; LUCA, Márcia M. M.; CORRÊA, Denise M. M. C.; OLIVEIRA, Marcelle C. A Auditoria Ambiental como Instrumento Gerencial de Apoio à Preservação do Meio Ambiente. In: South American Congress on Social and Environmental Accounting Research - CSEAR 2009, 1, Rio de Janeiro, 2009. Anais eletrônicos.... Disponível em: $<$ http://www.atena.org.br/revista/ojs-2.2.3-06/index.php/ufrj/article/viewFile/767/776>. Acesso em: 21 Set. 2013.

SILVA, Irene C.; PEREIRA, Ana Carlina T.; PESTANA, Carlile S.; SANTOS, Fernando H. G.; GARCIA, Henrique C.; SILVA, Stella L. A. A Contabilidade como instrumento de auxilio no controle do meio ambiente. Colloquium Humanarum, v. 10, n. Especial, p. 546552, Jul./Dez. 2013.

SOUZA Carlos C.; VILELA, Francini T. C. V.; OLIVEIRA, Marciano T.; VIEIRA, Renata S. Contabilidade Ambiental: pequenas atitudes grandes mudanças. Revista Gestão em Foco, Edição nº 07, 2015. Disponível em: <

http://unifia.edu.br/revista_eletronica/revistas/gestao_foco/artigos/ano2015/contab_ambiental. pdf $>$. Acesso em: 24 Fev. 2015. 
SCHNEIDER, A.; MEINS, E. Two Dimensions of Corporate Sustainability Assessment: Towards a Comprehensive Framework. Business Strategy and the Environment, v. 21, n. 4, p. 211-222, may, 2012.

TINOCO, J.E.P; KRAEMER, Maria. E.P. Contabilidade e Gestão Ambiental: Gastos, Ativos, Passivos, Despesas (Custos) e Receitas Ambientais. $3^{\text {a }}$ edição. São Paulo. Atlas, 2011.

TINOCO, J.E.P; KRAEMER, Maria. E.P. Contabilidade e Gestão Ambiental: Gestão Ambiental: O que precisamos saber. $3^{\text {a }}$ edição. São Paulo. Atlas, 2011.

VELLANI, Cassio L.; RIBEIRÃO, Maisa S. A Sustentabilidade e a Contabilidade. In: IX SIMPÓSIO DE ADMINISTRAÇÃO DA PRODUÇÃO, LOGÍSTICA E OPERAÇÕES INTERNACIONAIS, 9, 2006, São Paulo (SP) Anais... São Paulo: FGV/EAESP, 2006. Disponível em: <

http://www.simpoi.fgvsp.br/arquivo/2006/artigos/e2006_t00241_pcn74374.pdf>. Acesso em: 28 Set. 2013.

WOLFF, Simone. Subsídios ao IV Relatório Nacional para a Convenção sobre Diversidade Biológica - CDB: Diagnóstico sobre a Legislação Ambiental Brasileira, 2009. Disponível em:

$<$ http://www.mma.gov.br/estruturas/sbf_chm_rbbio/_arquivos/legistacao_4_relatorio_cdb.pdf >. Acesso em: 20 Set. 2013.

YAMAGUCHI, Cristina Keiko. Contabilidade ambiental e o comprometimento das organizações com a responsabilidade ambiental. Revista Espacios, v. 33, n. 12, p. 6, 2012. Disponível em: < http://www.revistaespacios.com/a12v33n12/12331206.html\#uno>. Acesso em: 20 Jan. 2014. 